\title{
Influence of Genetic Variation in COMT on Cisplatin-Induced Nephrotoxicity in Cancer Patients
}

\author{
Bram C. Agema ${ }^{1,2, *} \oplus$, Stijn L.W. Koolen ${ }^{2,3}$, Mirjam de With ${ }^{1,2} \oplus$, Nadia van Doorn ${ }^{2}$, \\ Niels Heersche ${ }^{2}$, Esther Oomen-de Hoop ${ }^{2}$, Sabine Visser 4,5, Joachim G.J.V. Aerts 4,5, \\ Sander Bins ${ }^{2}$, Ron H.N. van Schaik ${ }^{1}$ and Ron H.J. Mathijssen ${ }^{2}$ \\ 1 Department of Clinical Chemistry, Erasmus University Medical Center, 3015 GD Rotterdam, \\ The Netherlands; m.dewith@erasmusmc.nl (M.d.W.); r.vanschaik@erasmusmc.nl (R.H.N.v.S.) \\ 2 Department of Medical Oncology, Erasmus MC Cancer Institute, Erasmus University Medical Center, \\ 3015 GD Rotterdam, The Netherlands; s.koolen@erasmusmc.nl (S.L.W.K.); \\ n.vandoorn@erasmusmc.nl (N.v.D.); n.heersche@erasmusmc.nl (N.H.); \\ e.oomen-dehoop@erasmusmc.nl (E.O.-d.H.); s.bins@erasmusmc.nl (S.B.); \\ a.mathijssen@erasmusmc.nl (R.H.J.M.) \\ Department of Clinical Pharmacy, Erasmus University Medical Center, 3015 GD Rotterdam, The Netherlands \\ 4 Department of Pulmonology, Erasmus University Medical Center, 3015 GD Rotterdam, The Netherlands; \\ s.visser.2@erasmusmc.nl (S.V.); j.aerts@erasmusmc.nl (J.G.J.V.A.) \\ 5 Department of Pulmonology, Amphia Hospital, 4818 CK Breda, The Netherlands \\ * Correspondence: b.agema@erasmusmc.nl
}

Received: 11 February 2020; Accepted: 25 March 2020; Published: 27 March 2020

check for updates

\begin{abstract}
Cisplatin is a chemotherapeutic agent widely used for multiple indications. Unfortunately, in a substantial set of patients treated with cisplatin, dose-limiting acute kidney injury (AKI) occurs. Here, we assessed the association of 3 catechol-O-methyltransferase (COMT) single nucleotide polymorphisms (SNPs) with increased cisplatin-induced nephrotoxicity. In total, 551 patients were genotyped for the 1947 G>A (Val158Met, rs4680), c.615 + 310 C>T (rs4646316), and c.616-367 C>T (rs9332377) polymorphisms. Associations between these variants and AKI grade $\geq 3$ were studied. The presence of a homozygous variant of c.616-367C $>\mathrm{T}$ was associated with a decreased occurrence of AKI grade 3 toxicity ( $p=0.014$, odds ratio (OR) $0.201,95 \%$ confidence interval (CI) (0.047-0.861)). However, we could not exclude the role of dehydration as a potential cause of AKI in 25 of the 27 patients with AKI grade 3, which potentially affected the results substantially. As a result of the low incidence of AKI grade 3 in this dataset, the lack of patients with a COMT variant, and the high number of patients with dehydration, the association between COMT variants and AKI does not seem clinically relevant.
\end{abstract}

Keywords: cisplatin; acute kidney injury; COMT; nephrotoxicity; SNP

\section{Introduction}

Cisplatin is a widely used cytostatic agent that interferes with DNA replication by binding within (and between) DNA strands resulting in the inhibition of protein synthesis and DNA replication. It is approved for the treatment of many types of cancer such as testicular seminoma, non-small cell lung cancer, and head and neck cancer [1]. Common toxicities associated with cisplatin treatment include nephrotoxicity, ototoxicity, and leukopenia, of which nephrotoxicity is the main cause of dose reduction or even termination of systemic therapy. Treatment-related acute kidney injury (AKI) occurs in 20-30\% of cisplatin-treated patients and is dose-dependent [2].

In a recently published case report, the potential role of catechol-O-methyltransferase (COMT) on cisplatin-induced nephrotoxicity was suggested [3]. Single nucleotide polymorphisms (SNPs) in five 
candidate genes, of which two are SNPs in COMT, were genotyped in a young woman who developed severe irreversible cisplatin-induced nephropathy. Both COMT polymorphisms were already known to be associated with cisplatin induced ototoxicity $[4,5]$ and were homozygous polymorphic in this patient (c.615 + 310C > T (rs4646316) and c.616-367C > T (rs9332377)) [3]. As COMT is an enzyme that inactivates catecholamines by transferring a methyl group of S-adenosyl methionine (SAM) into a catecholamine neurotransmitter (such as dopamine, epinephrine, and norepinephrine), the authors hypothesized that the mechanism of cisplatin-induced nephrotoxicity could be mediated by increased SAM concentrations. This theory is supported by data from a mouse model study where cisplatin toxicity was 3- to 6-fold increased when SAM and cisplatin were administered concomitantly, compared to cisplatin administration alone [6]. The association between these two COMT polymorphisms and cisplatin-induced nephrotoxicity has not been validated in further clinical research.

Another polymorphism in the COMT gene, the COMT 1947G >A (rs4680), is also known to affect COMT function [7]. This SNP is associated with response to other drugs [8-11], but has not been tested yet for the association with cisplatin-induced AKI.

Here, we studied the association between these three COMT polymorphisms and cisplatin-induced nephrotoxicity in a large cohort of cancer patients in order to assess the clinical relevance of these SNPs and their potential use as predictor in this context.

\section{Methods}

\subsection{Study Design}

Patients treated with cisplatin at the Erasmus MC Cancer Institute according to standard of care between January 2004 and April 2019 and who provided informed consent to prospectively perform DNA genotyping in their blood samples (Erasmus MC institutional review board study number MEC 02.1002) were included in this genetic association study. Patients treated with cisplatin and pemetrexed in the PERSONAL (PEmetrexed and biomaRkerS: an observatiONAL) study were also included in this analysis [12]. All patients were advised to drink two liters of water a day during cisplatin treatment and four liters of glucose $/ \mathrm{NaCl} / \mathrm{KCl} / \mathrm{MgSO}_{4}$ solution was administered intravenously in $24 \mathrm{~h}$ on the day of cisplatin administration. The most recent plasma creatinine concentrations within two weeks prior to the first cisplatin administration were used as a baseline value. The highest plasma creatinine concentration within the period of first cisplatin administration until three weeks after the second 3-weekly administration was used for statistical analysis. Patients were excluded if baseline or on-treatment creatinine concentrations were not available or if the cisplatin dosage was not clearly recorded.

\subsection{Classification of Endpoints and Adverse Events}

AKI was graded according to the Common Terminology Criteria of Adverse Events (CTCAE) version 4.03 (Table 1) [13]. AKI grade 3 or higher was interpreted as 'severe $\mathrm{AKI}^{\prime}$ ', and was, therefore, the primary outcome in this study.

Of patients with AKI grade 3 or higher, the patient files were studied for potential confounders, such as dehydration and renal and post-renal pathology and recovery. When the plasma creatinine concentrations of these patients did not return to baseline $+20 \mu \mathrm{mol} / \mathrm{L}$ in 2 years after cisplatin administration, this was classified as irreversible cisplatin-induced nephrotoxicity.

\subsection{DNA Isolation and TaqManßGenotyping}

DNA was isolated using the MagNA Pure 96 Instrument (Roche Diagnostics GmbH, Rotkreuz, Switzerland), from $500 \mu \mathrm{L}$ of the whole-blood specimens using the MagNA Pure 96 DNA and Viral Large Volume Kit (Roche Diagnostics GmbH, Rotkreuz, Switzerland). The selected COMT SNPs were genotyped using predesigned Drug Metabolism Enzymes TaqMan®allelic discrimination assays on the Life Technologies TaqMan®7500 system (Applied Biosystems, Life Technologies Europe BV, Bleijswijk, 
The Netherlands). Assay IDs are listed in Table 2. Each assay contains assay-specific primers and allele-specific minor groove binding probes labelled with $\mathrm{VIC}^{\mathrm{TM}}$ and $\mathrm{FAM}^{\mathrm{TM}}$ fluorescent dyes. Using these assays, TaqMan®GTXpress Master Mix and $20 \mu \mathrm{g}$ genomic DNA, the polymerase chain reactions were performed in a reaction volume of $12 \mu \mathrm{L}$. The thermal profile of the TaqMan $₫ q P C R$ reaction consisted of 40 cycles of denaturation $\left(95^{\circ} \mathrm{C}\right.$ for $\left.20 \mathrm{~s}\right)$, annealing $\left(92^{\circ} \mathrm{C}\right.$ for $\left.3 \mathrm{~s}\right)$, and extension $\left(60^{\circ} \mathrm{C}\right.$ for $30 \mathrm{~s})$. Genotypes were determined by measuring allele-specific fluorescence using the TaqMan $§ 7500$ software v2.3 for allelic discrimination.

Table 1. Definition of Common Terminology Criteria of Adverse Events (CTCAE) and Kidney Disease: Improving Global Outcomes (KDIGO) grading of acute kidney disease (AKI) in adults [13,14].

\begin{tabular}{|c|c|c|c|c|}
\hline \multicolumn{2}{|r|}{ CTCAE } & \multicolumn{3}{|c|}{ KDIGO } \\
\hline Grade & Serum creatinine & Stage & Serum creatinine & Urine output \\
\hline 1 & $\begin{array}{c}1.5-2.0 \times \text { baseline; OR } \\
\geq 0.3 \mathrm{mg} / \mathrm{dL}(26.5 \mu \mathrm{mol} / \mathrm{L}) \text { increase }\end{array}$ & 1 & $\begin{aligned} & 1.5-1.9 \times \text { baseline; OR } \\
\geq & 0.3 \mathrm{mg} / \mathrm{dL}(26.5 \mu \mathrm{mol} / \mathrm{L}\end{aligned}$ & $<0.5 \mathrm{~mL} / \mathrm{kg} / \mathrm{h}$ for $6-12 \mathrm{~h}$ \\
\hline 2 & 2.0-3.0 $\times$ baseline & 2 & 2.0-2.9 $\times$ baseline & $<0.5 \mathrm{~mL} / \mathrm{kg} / \mathrm{h}$ for $\geq 12 \mathrm{~h}$ \\
\hline 3 & $\begin{array}{c}>3.0 \times \text { baseline; OR } \\
>4.0 \mathrm{mg} / \mathrm{dL}(353.6 \mu \mathrm{mol} / \mathrm{L}) \text { increase; } \\
\text { OR } \\
\text { Hospitalization indicated }\end{array}$ & 3 & $\begin{array}{c}3.0 \times \text { baseline; OR } \\
\geq 4.0 \mathrm{mg} / \mathrm{dL}(353.6 \mu \mathrm{mol} / \mathrm{L}) \\
\text { increase; OR } \\
\text { Initiation of renal } \\
\text { replacement therapy }\end{array}$ & $\begin{array}{c}<0.3 \mathrm{~mL} / \mathrm{kg} / \mathrm{h} \text { for } \geq 24 \mathrm{~h} ; \\
\text { OR } \\
\text { anuria for } \geq 12 \mathrm{~h}\end{array}$ \\
\hline 4 & $\begin{array}{l}\text { Life-threatening consequences; OR } \\
\text { Dialysis indicated }\end{array}$ & & & \\
\hline 5 & Death & & & \\
\hline
\end{tabular}

Table 2. Details and distributions of the studied single nucleotide polymorphisms (SNPs).

\begin{tabular}{|c|c|c|c|c|c|c|c|c|}
\hline Gene & rs number & Variant & Assay ID & WT & HT & HM & MAF & HW \\
\hline \multirow{3}{*}{ COMT } & rs4646316 & c. $615+310 \mathrm{C}>\mathrm{T}$ & C__29193982_10 & 316 & 204 & 31 & $24 \%$ & 0.80 \\
\hline & rs9332377 & c.616-367C > T & C_29614343_10 & 400 & 140 & 11 & $15 \%$ & 0.76 \\
\hline & rs4680 & c.472G $>$ A (Val158Met) & C_25746809_50 & 117 & 282 & 152 & $53 \%$ & 0.51 \\
\hline
\end{tabular}

WT, wildtype; HT, heterozygous variant; HM, homozygous variant; MAF, minor allele frequency; HW,

Hardy-Weinberg P value

\subsection{Statistical Analysis}

Distribution of genotypes was tested for Hardy Weinberg equilibrium; if $p<0.05$, the genotype was excluded from analysis. The minor allele frequency (MAF) was also determined and compared to the MAF in the literature (Table 2).

Associations of the SNPs with the endpoints were tested in the dominant model; heterozygous variant (HT) and homozygous variant (HM) versus wildtype (WT), or the recessive model; and HM versus HT and WT. Prior research was reviewed to determine if the variant affected the SNP in a recessive or dominant manner. COMT 616-367C $>$ T and $1947 \mathrm{G}>\mathrm{A}$ were tested in the dominant model [4,15]. COMT 615+310 C $>\mathrm{T}$ was tested using the recessive model [4]. For both the dominant and recessive models, the chi-squared test or Fisher's exact test was used, depending on the cell counts of the contingency tables. When the cell count in any of the tables was less than 10, Fisher's exact test was used.

Univariable associations of AKI with COMT polymorphisms $p<0.1$ were considered for multivariable logistic regression analysis together with baseline variables such as age, gender, and cisplatin dosage, if possible. When Fishers' exact test was used, no multivariable analysis was performed due to the large influence of chance on the outcome.

\section{Results}

\subsection{Patients}

A total of 551 patients, with different malignancies, were included in this study. All genotypes were in Hardy-Weinberg equilibrium (Table 2). Baseline characteristics of these patients are depicted 
in Table 3. None of the included patients had renal dysfunction at baseline. Compared with baseline, median increase in plasma creatinine values was $10 \mu \mathrm{mol} / \mathrm{L}$ (interquartile range (IQR) 3-21 $\mu \mathrm{mol} / \mathrm{L}$ ) during treatment. AKI grade 3 occurred in 27 patients $(5 \%)$.

Table 3. Patient characteristics.

\begin{tabular}{|c|c|c|}
\hline Characteristics & Controls, $n=524$ & AKI grade $3(n=27)$ \\
\hline \multicolumn{3}{|l|}{ Gender (n) } \\
\hline - Male & $310(59 \%)$ & $20(74 \%)$ \\
\hline - Female & $214(39 \%)$ & $7(26 \%)$ \\
\hline \multicolumn{3}{|l|}{ Age (years) } \\
\hline - Median (IQR) & $57(45-65)$ & $62(57-66)$ \\
\hline \multicolumn{3}{|l|}{ Primary tumour $(\mathrm{n})$} \\
\hline - Pulmonary & $139(27 \%)$ & $4(15 \%)$ \\
\hline - Gastrointestinal & $121(23 \%)$ & $2(7 \%)$ \\
\hline - Testicular & $71(14 \%)$ & $1(4 \%)$ \\
\hline - Gynaecological & $66(13 \%)$ & $3(11 \%)$ \\
\hline - Head / neck & $56(11 \%)$ & $14(52 \%)$ \\
\hline - Other & $71(14 \%)$ & $3(11 \%)$ \\
\hline \multicolumn{3}{|l|}{ Baseline plasma creatinine concentrations } \\
\hline - Median (IQR) $(\mu \mathrm{mol} / \mathrm{L})$ & $69(59-81)$ & $70(64-77)$ \\
\hline - Median (IQR) (mg/dL) & $0.78(0.67-0.92)$ & $0.79(0.72-0.87)$ \\
\hline \multicolumn{3}{|l|}{ eGFR } \\
\hline - Median CKD-EPI (IQR) (mL/min) & $98(85-106)$ & $95(81-99)$ \\
\hline \multicolumn{3}{|l|}{ Peak creatinine concentrations } \\
\hline - Median (IQR) ( $\mu \mathrm{mol} / \mathrm{L})$ & $81(69-96)$ & $131(117-166)$ \\
\hline - Median (IQR) (mg/dL) & $0.92(0.78-1.09)$ & $1.48(1.32-1.88)$ \\
\hline \multicolumn{3}{|l|}{ eGFR } \\
\hline - Median CKD-EPI (IQR) (mL/min) & $87(70-99)$ & $44(35-51)$ \\
\hline Dehydration as potential cause of AKI (n) & N/A & $25(93 \%)$ \\
\hline Irreversible creatinine augmentation (n) & N/A & $4(15 \%)$ \\
\hline \multicolumn{3}{|l|}{ Cisplatin dosage (n) } \\
\hline$-<50 \mathrm{mg} / \mathrm{m}^{2}$ & $119(23 \%)$ & $10(37 \%)$ \\
\hline$-50-79 \mathrm{mg} / \mathrm{m}^{2}$ & $298(57 \%)$ & $12(44 \%)$ \\
\hline$-\geq 80 \mathrm{mg} / \mathrm{m}^{2}$ & $107(20 \%)$ & $5(19 \%)$ \\
\hline
\end{tabular}

\subsection{Effect of COMT SNPS on Nephrotoxicity}

All tested associations between the SNPs and AKI grade 3 are displayed in Table 4. COMT c.616-367C $>$ T was significantly associated with less AKI grade 3 when performing a dominant analysis $(\mathrm{CT}+\mathrm{TT}$ vs. CC, $p=0.014$, odds ratio (OR) $0.20195 \%$ confidence interval (CI) (0.047-0.861)). Age $\geq 65$ years was univariably associated with the incidence of AKI grade 3 ( $p=0.025$, OR 2.464, 95\% CI (1.095-5.542)) but dosage $\geq 80 \mathrm{mg} / \mathrm{m}^{2}$ and gender were not (Table 4). Association between the SNPs and $\Delta$ estimated glomerular filtration rate (eGFR) was also tested (Supplementary Table S1).

Upon analysis of patient files of the patients with AKI grade 3, the creatinine concentration did not return to baseline in four out of 27 patients. In 25 out of 27 patients that had AKI grade 3, dehydration could not be excluded as a potential cause of AKI (Table 3).

COMT 1947G > A and COMT c.615 + 310C > T were not significantly associated with AKI.

Table 4. Associations of AKI grade 3 with SNPs and confounders and the number of AKI grade 3 per patient group.

\begin{tabular}{|c|c|c|c|c|}
\hline \multirow{2}{*}{ Endpoint } & \multirow{2}{*}{ Factor } & \multirow{2}{*}{ Groups (AKI grade 3/patients) } & \multicolumn{2}{|c|}{ Univariable } \\
\hline & & & $\mathrm{OR}^{\mathrm{V}}(95 \% \mathrm{CI})$ & $p$-value \\
\hline \multirow{6}{*}{ AKI grade 3} & COMT $(615+310 \mathrm{C}>\mathrm{T})$ & TT (4/31) vs CC + CT (23/520) & 3.201 (1.034-9.912) & $0.058 *$ \\
\hline & COMT $(616-367 \mathrm{C}>\mathrm{T})$ & $\mathrm{CT}+\mathrm{TT}(2 / 151)$ vs CC $(25 / 400)$ & $0.201(0.047-0.861)$ & 0.014 * \\
\hline & COMT (1947G >A) & $\mathrm{GA}+\mathrm{AA}(21 / 434)$ vs GG (6/117) & $1.063(0.419-2.697)$ & 0.814 * \\
\hline & Age $\geq 65$ & $\geq 65(10 / 111)$ vs $<65(17 / 440)$ & $2.464(1.095-5.542)$ & 0.025 \\
\hline & Dosage $\geq 80 \mathrm{mg} / \mathrm{m}^{2}$ & $\geq 80(7 / 112)$ vs $<80(20 / 439)$ & $1.397(0.575-3.391)$ & 0.464 * \\
\hline & Gender & Male (20/310) vs Female $(7 / 221)$ & $1.972(0.820-4.746)$ & 0.159 * \\
\hline
\end{tabular}

* Fisher's exact test, ${ }^{\gamma}$ Odds ratio of 'Groups'. 
None of the associations could be tested multivariably as all genetic associations were tested using Fishers' exact test.

\section{Discussion}

This was the first study in which the association of COMT SNPs with cisplatin-induced AKI was assessed. Although we found a significant association between COMT c.616-367 C>T and cisplatin-induced AKI grade 3, we cannot rule out that this result was affected by dehydration, which we could not exclude in 25 of 27 patients. Insufficient data regarding hydration state was available as the data collection was performed retrospectively. The association of dehydration could, therefore, not be statistically tested in this cohort. However, as 25 patients with AKI grade 3 were potentially dehydrated according to their patient files, this could indicate that dehydration is a more important factor in the development of AKI than COMT SNPs.

Despite this large cohort of patients treated with cisplatin, the occurrence of AKI grade 3 was insufficient to perform the chi-square test, and, therefore, did not comply with the requirements for multivariable analysis as stated in the methods section. An analysis using any AKI was not performed as this would not be clinically relevant. The occurrence of AKI grade 1 or 2 would not lead to dose reduction or treatment delay. As all but four patients with AKI grade 3 ultimately had complete recovered renal function, the underlying pathophysiological mechanism seems to point at a prerenal cause of AKI, which was most likely caused by dehydration. Moreover, based on the physiological mechanism, one would expect that patients harboring this polymorphism would be at more risk of developing AKI grade 3, rather than at reduced risk as we found. Additionally, the other investigated SNPs in COMT were not significantly associated with AKI grade 3. These data do, therefore, not provide a rationale for pre-emptive genotyping of COMT.

Of the patients who developed AKI grade 3,52\% were diagnosed with head or neck tumors (Table 3). Thirteen out of these 14 patients with this tumor type were treated by chemoradiotherapy (including cisplatin) which caused mucositis in up to $97 \%$ of the patients [16]. Oral mucositis can cause severe pain, which complicates drinking and is, therefore, a causal factor for dehydration. The fact that head and neck tumors are overrepresented in this group underlines the plausibility that AKI grade 3 in most of the patients was caused by dehydration. The standard use of prehydration and posthydration schemes show that many efforts are being made to prevent cisplatin-induced nephrotoxicity. Nonetheless, these efforts do not guarantee that the kidney function will remain stable during treatment.

The size of the studied patient population, which was prospectively identified, allowed us to study a relatively large number of patients with cisplatin-induced AKI. However, the retrospective collection of clinical data comes with several limitations. As we studied plasma creatinine concentrations, exact pathophysiological mechanisms of kidney injury could not be retrieved. In most patients, dehydration had to be determined by anamnestic information and (the time of) recovery after rehydration. Data on possible confounders such as fluid intake, co-medication, diarrhea, and nausea were not available and, due to the small sample size, could not be adjusted for in a multivariate analysis. However, these factors as a possible cause of AKI must be taken into account during cisplatin treatment. Other causes of AKI grade 3 have not been investigated regularly and urinalysis was performed only in a minority of patients. Moreover, there was large heterogeneity in the interval between blood draws, since these were only regularly scheduled in advance of each chemotherapy cycle and additional blood draws were executed based on clinical judgement of symptoms and hydration status. Therefore, temporary and asymptomatic elevations in plasma creatinine might have been missed in this study.

Cisplatin-induced nephrotoxicity is currently mostly prevented with hyperhydration, magnesium supplementation or mannitol-induced forced diuresis, whereas none of these measures will guarantee that kidney function will remain stable [17]. Amifostine and cimetidine exert serious side effects and offer only a partial degree of nephroprotection against cisplatin nephrotoxicity [18-21]. Erlotinib has been suggested to have a beneficial effect on cisplatin nephrotoxicity by competitively inhibiting the 
OCT2 enzyme. This has not been validated yet [22]. So far, no perfect prevention is present, which renders the search for predictors of important dose limited toxicities of cisplatin still relevant.

In conclusion, we found that COMT c.616-367 C > T is significantly protectively associated with the incidence of AKI grade 3 during cisplatin treatment. Despite the considerable size of this cohort, there was insufficient power and lack of data on hydration state to investigate the extent in which possible confounders such as dehydration affected this result. This study did not provide a rationale for pre-emptive genotyping of COMT SNPs to predict AKI in patients treated with cisplatin. The retrospective nature of this study necessitates prospective validation.

Supplementary Materials: The following are available online at http://www.mdpi.com/2073-4425/11/4/358/s1, Table S1: Associations of $\triangle \mathrm{eGFR}$ with SNPs and confounders.

Author Contributions: Concept and design: B.C.A., S.L.W.K., M.d.W., S.B., R.H.N.v.S., and R.H.J.M. Data collection: B.C.A., N.v.D., N.H., and S.V. SNP analysis: B.C.A. Statistical analysis: E.O.-d.H., and B.C.A. Drafting of the manuscript: B.C.A., S.L.W.K., M.d.W., S.B. and R.H.J.M. Reviewing the manuscript: All authors. All authors have read and agreed to the published version of the manuscript.

Funding: The authors received no funding for conducting this study.

Conflicts of Interest: The authors declare no conflict of interest. This study was presented at the European Society for Medical Oncology (ESMO) congress 2019 (30 September, Barcelona, Spain, abstract \#5044).

\section{References}

1. Cisplatine, Informatorium Medicamentorum. KNMP Kennisbank; KNMP: The Hague, The Netherlands, 2019.

2. Miller, R.P.; Tadagavadi, R.K.; Ramesh, G.; Reeves, W.B. Mechanisms of Cisplatin nephrotoxicity. Toxins (Basel) 2010, 2, 2490-2518. [CrossRef] [PubMed]

3. De Jong, C.; Sanders, S.; Creemers, G.J.; Burylo, A.M.; Taks, M.; Schellens, J.H.M.; Deenen, M.J. Pharmacogenetic analysis of irreversible severe cisplatin-induced nephropathy: A case report of a 27-year-old woman. Br. J. Clin. Pharmacol. 2017, 83, 2120-2122. [CrossRef] [PubMed]

4. Ross, C.J.; Katzov-Eckert, H.; Dube, M.P.; Brooks, B.; Rassekh, S.R.; Barhdadi, A.; Feroz-Zada, Y.; Visscher, H.; Brown, A.M.; Rieder, M.J.; et al. Genetic variants in TPMT and COMT are associated with hearing loss in children receiving cisplatin chemotherapy. Nat. Genet. 2009, 41, 1345-1349. [CrossRef] [PubMed]

5. Yang, J.J.; Lim, J.Y.; Huang, J.; Bass, J.; Wu, J.; Wang, C.; Fang, J.; Stewart, E.; Harstead, E.H.; Robinson, G.W.; et al. The role of inherited TPMT and COMT genetic variation in cisplatin-induced ototoxicity in children with cancer. Clin. Pharmacol. Ther. 2013, 94, 252-259. [CrossRef] [PubMed]

6. Ochoa, B.; Bobadilla, N.; Arrellin, G.; Herrera, L.A. S-Adenosyl-L-methionine increases serum BUN and creatinine in cisplatin-treated mice. Arch. Med. Res. 2009, 40, 54-58. [CrossRef] [PubMed]

7. Egan, M.F.; Goldberg, T.E.; Kolachana, B.S.; Callicott, J.H.; Mazzanti, C.M.; Straub, R.E.; Goldman, D.; Weinberger, D.R. Effect of COMT Val108/158 Met genotype on frontal lobe function and risk for schizophrenia. Proc. Natl. Acad. Sci. USA 2001, 98, 6917-6922. [CrossRef] [PubMed]

8. Porcelli, S.; Drago, A.; Fabbri, C.; Gibiino, S.; Calati, R.; Serretti, A. Pharmacogenetics of antidepressant response. J. Psychiatry Neurosci. 2011, 36, 87-113. [CrossRef] [PubMed]

9. Chen, J.; Lipska, B.K.; Halim, N.; Ma, Q.D.; Matsumoto, M.; Melhem, S.; Kolachana, B.S.; Hyde, T.M.; Herman, M.M.; Apud, J.; et al. Functional analysis of genetic variation in catechol-O-methyltransferase (COMT): Effects on mRNA, protein, and enzyme activity in postmortem human brain. Am. J. Hum. Genet. 2004, 75, 807-821. [CrossRef] [PubMed]

10. Matic, M.; de Wildt, S.N.; Tibboel, D.; van Schaik, R.H.N. Analgesia and Opioids: A Pharmacogenetics Shortlist for Implementation in Clinical Practice. Clin. Chem. 2017, 63, 1204-1213. [CrossRef] [PubMed]

11. He, Q.; Xue, G.; Chen, C.; Lu, Z.L.; Chen, C.; Lei, X.; Liu, Y.; Li, J.; Zhu, B.; Moyzis, R.K.; et al. COMT Val158Met polymorphism interacts with stressful life events and parental warmth to influence decision making. Sci. Rep. 2012, 2, 677. [CrossRef] [PubMed]

12. Visser, S.; Huisbrink, J.; van't Veer, N.E.; van Toor Jermo, J.; van Boxem, A.J.M.; van Walree, N.C.; Stricker Bruno, H.; Aerts, J.G.J.V. Renal impairment during pemetrexed maintenance in patients with advanced nonsmall cell lung cancer: A cohort study. Eur. Respir. J. 2018, 52, 1800884. [CrossRef] [PubMed] 
13. Common Terminology Criteria for Adverse Events (CTCAE). Edservices USdohah; National Institutes of Health: Bethesda, MD, USA, 2010.

14. KDIGO. Clinical Practice Guideline for Acute Kidney Injury. Section 2: AKI defenition. Kidney Int. Suppl. 2012, 2, 1.

15. Elens, L.; Norman, E.; Matic, M.; Rane, A.; Fellman, V.; van Schaik, R.H. Genetic Predisposition to Poor Opioid Response in Preterm Infants: Impact of KCNJ6 and COMT Polymorphisms on Pain Relief After Endotracheal Intubation. Ther. Drug Monit. 2016, 38, 525-533. [CrossRef] [PubMed]

16. Curra, M.; Soares Junior, L.A.V.; Martins, M.D.; Santos, P. Chemotherapy protocols and incidence of oral mucositis. An integrative review. Einstein (Sao Paulo) 2018, 16, eRW4007. [CrossRef] [PubMed]

17. Crona, D.J.; Faso, A.; Nishijima, T.F.; McGraw, K.A.; Galsky, M.D.; Milowsky, M.I. A Systematic Review of Strategies to Prevent Cisplatin-Induced Nephrotoxicity. Oncologist 2017, 22, 609-619. [CrossRef] [PubMed]

18. Capizzi, R.L. Amifostine reduces the incidence of cumulative nephrotoxicity from cisplatin: Laboratory and clinical aspects. Semin. Oncol. 1999, 26, 72-81. [PubMed]

19. Rades, D.; Fehlauer, F.; Bajrovic, A.; Mahlmann, B.; Richter, E.; Alberti, W. Serious adverse effects of amifostine during radiotherapy in head and neck cancer patients. Radiother. Oncol. 2004, 70, 261-264. [CrossRef] [PubMed]

20. Filipski, K.K.; Mathijssen, R.H.; Mikkelsen, T.S.; Schinkel, A.H.; Sparreboom, A. Contribution of organic cation transporter 2 (OCT2) to cisplatin-induced nephrotoxicity. Clin. Pharmacol. Ther. 2009, 86, 396-402. [CrossRef] [PubMed]

21. Sprowl, J.A.; van Doorn, L.; Hu, S.; van Gerven, L.; de Bruijn, P.; Li, L.; Gibson, A.A.; Mathijssen, R.H.; Sparreboom, A. Conjunctive therapy of cisplatin with the OCT2 inhibitor cimetidine: Influence on antitumor efficacy and systemic clearance. Clin. Pharmacol. Ther. 2013, 94, 585-592. [CrossRef] [PubMed]

22. Sprowl, J.A.; Mathijssen, R.H.; Sparreboom, A. Can erlotinib ameliorate cisplatin-induced toxicities? J. Clin. Oncol. 2013, 31, 3442-3443. [CrossRef] [PubMed]

(C) 2020 by the authors. Licensee MDPI, Basel, Switzerland. This article is an open access article distributed under the terms and conditions of the Creative Commons Attribution (CC BY) license (http://creativecommons.org/licenses/by/4.0/). 